\title{
Evaluation of two interforaminal implants and implant-assisted removable dentures on stress distribution: an in vitro study
}

\author{
Selda Arat Bilhan ${ }^{1}$, Onur Geckili ${ }^{2}$, Altug Cilingir ${ }^{3}$, Ergun Bozdag ${ }^{4}$, Hakan Bilhan ${ }^{5}$ \\ ${ }^{1}$ Private Office, Waltrop, Germany, \\ ${ }^{2}$ Department of Prosthodontics, Faculty of Dentistry, Istanbul University, Istanbul, \\ ${ }^{3}$ Department of Prosthodontics, Faculty of Dentistry, Trakya University, Edirne, \\ ${ }^{4}$ Lab of Strength of Materials and Biomechanics, Faculty of Mechanical Engineering, Istanbul Technical University, Istanbul, Turkey, \\ ${ }^{5}$ Department of Periodontology, School of Dentistry, Faculty of Health, University Witten/Herdecke, Witten, Germany
}

\begin{abstract}
J Korean Assoc Oral Maxillofac Surg 2019;45:199-206)
Objectives: In mandibular edentulism, the treatment option with a two-interforaminal implant-retained bridge and a removable partial denture is rarely evaluated in literature. The aim of this in vitro study was to evaluate the stress distribution of this treatment option by comparing it with traditional treatment options with interforaminal implants in the edentulous mandible.

Materials and Methods: Two interforaminal implants were placed in a formalin-fixed cadaver mandible, and overdentures with three different types of attachments were fabricated: (1) two ball attachments and an overdenture, (2) a Dolder bar and an overdenture, and (3) screw-retained two-implant inter-canine porcelain fused to a metal bridge and an implant-assisted removable denture (IARD) with precision attachments. Three biting conditions were generated for each denture type, and the strains were documented under vertical loading of $100 \mathrm{~N}$.

Results: The calculated strain values from measured strains in all measurement sites and loading conditions for the screw-retained two-implant intercanine porcelain fused to a metal bridge and a cast framework partial denture with precision attachments situation were lower than in the other scenarios $(P<0.05)$.

Conclusion: Within the limitations of the present study, it can be concluded that an IARD may be a reasonable and valuable alternative to ball attachments or a bar in two interforaminal implants, especially when the patients prefer to be able to show their teeth even when they take out their removable dentures.
\end{abstract}

Key words: Implant, Strain gauge, Removable denture, Overdenture, Dental

[paper submitted 2018. 8. 2 / revised 1st 2018. 9. 14, 2nd 2018. 10. 2 / accepted 2018. 10. 5]

\section{Introduction}

Two implants are considered the minimum necessity to retain a mandibular denture in edentulous patients ${ }^{1,2}$. Previous studies have shown that mandibular two-implant-supported overdentures (ISRDs) provide significant enhancement in stability, retention, patient satisfaction, and quality of life ${ }^{3-6}$.

\section{Onur Geckili \\ Department of Prosthodontics, Faculty of Dentistry, Istanbul University, 2nd Floor, Istanbul 34093, Turkey \\ TEL: +90-212-4142020 FAX: +90-212-5253585 \\ E-mail: geckili@istanbul.edu.tr \\ ORCID: https://orcid.org/0000-0002-7852-3915}

(c) This is an open-access article distributed under the terms of the Creative Commons Attribution Non-Commercial License (http://creativecommons.org/ licenses/by-nc/4.0/), which permits unrestricted non-commercial use, distribution, and reproduction in any medium, provided the original work is properly cited. Copyright (C) 2019 The Korean Association of Oral and Maxillofacial Surgeons. All rights reserved.
ISRDs may be used either with single attachments or attachments splinted together using a cast metal bar and clips ${ }^{7}$. Several types of single attachments are available for ISRDs such as ball attachments, locators, magnets, and rigid or non-rigid telescopic copings ${ }^{8,9}$.

The indications for different attachment systems for ISRDs are well-documented in literature, but some controversial opinions exist ${ }^{10-12}$. However, no significant difference in satisfaction level ${ }^{13-16}$ and quality of life $\mathrm{e}^{17,18}$ were reported by patients receiving various attachment types of overdentures except for a few studies concerning magnetic attachments ${ }^{19,20}$. The results of several clinical studies indicate that the retention mechanisms have similar effects on marginal bone levels ${ }^{21-23}$. Still, there is no consensus opinion ${ }^{24,25}$ about the influence of attachment systems on patient satisfaction or marginal bone level maintenance ${ }^{26}$ around supporting im- 
plants. Since overloading of ISRDs may lead to bone loss at the implant-bone interface ${ }^{27,28}$, it is important to evaluate the influence of possible variables on load distribution in bone and around implants. In a recent clinical study, no statistically significant differences were found between single and bar attachment types, although the bone loss rate observed in those with single attachments tended to be lower ${ }^{29}$. On the other hand, as splinted implants act together as a group, less bone loss due to distribution of the loads by splinting of the implants can be expected ${ }^{30}$.

Although it is not a common type of implant superstructure, an implant-assisted removable denture (IARD) can be fabricated instead of an ISRD in cases with few anterior implants. In most IARDs, implants are placed under conventional removable partial dentures (RPDs) with abutment teeth to optimize stability and retention of the prosthesis ${ }^{31}$. This solution has shown a more helpful effect on oral health compared to conventional RPDs ${ }^{32,33}$. While these advantages advocated for IARD treatment in the early $2000 \mathrm{~s}^{31,34}$, clinical studies evaluating its technical features and performance are scarce. A recent literature review reported that treatment with IARDs is a simple and cost-effective approach, but the absence of robust publications related to IARDs has limited significant conclusions ${ }^{31}$. Likewise, offering IARDs to edentulous patients as an alternative to ISRDs has been published only in case studies ${ }^{34-37}$. The consensus that had been reached in these reports ${ }^{34-37}$ was increased satisfaction due to the resolved need to remove anterior teeth during sleep or oral hygiene maintenance as with ISRDs. With this solution, patients reported increased confidence since the anterior part of the prosthesis is fixed and more comfortable due to reduced denture volume ${ }^{34,35}$. Furthermore, this treatment option fulfills patient desire to show their teeth even after removal of the mandibular denture ${ }^{36}$. Therefore, this in vitro study was conducted to observe if the stress distribution in the mandible is advantageous for this type of prosthetic alternative or if it has a detrimental effect on force distribution.

Whether this kind of superstructure will reduce or increase maintenance requirements will be the subject of another clinical study. This in vitro study was performed to test different scenarios in terms of the influence of types of attachment and superstructure on stress distribution in the edentulous mandible. The null hypothesis of the study was that IARD and ISRD would not have a significant difference on stress distribution in the edentulous mandible.

\section{Materials and Methods}

An edentulous mandible from a formalin-fixed human cadaver was selected from the Department of Anatomy, Faculty of Medicine, Istanbul University to use in this in vitro strain gauge (SG) measurement study. After removal of the mandible from the cadaver, locations where the $\mathrm{SG}$ rosettes (CEA 125UR, $350 \Omega$; Vishay Precision Group Inc., Malvern, PA, USA) would be applied were cleaned using pure alcohol. Surface smoothing was accomplished through the two-stage application of sandpaper. Six SG rosettes were applied at the following locations:

1) Right mylohyoid ridge (MRR)

2) Left mylohyoid ridge (MRL)

3) Symphysis midline (SM)

4) Right retromolar pad (RP)

5) Buccal shelf left (BP)

6) Right canine region $(\mathrm{C})$

The SGs were adapted, bonding material (M-Bond; Vishay Micro-Measurements, Raleigh, NC, USA) was applied to the bone, and the gauges were fastened to the bone to finger pressure. All connections were soldered afterward. After this process was complete, all single elements of the rosettes were circuit balanced and shunt calibrated electronically in situ. (Fig. 1)

A 2-mm-thick polyvinylsiloxane impression material (Affinis light body, Coltene/Whaledent AG, Altstätten, Switzerland) was adapted to the mandible to mimic soft tissue.(Fig. 2) An impression was fabricated from the equipped mandible

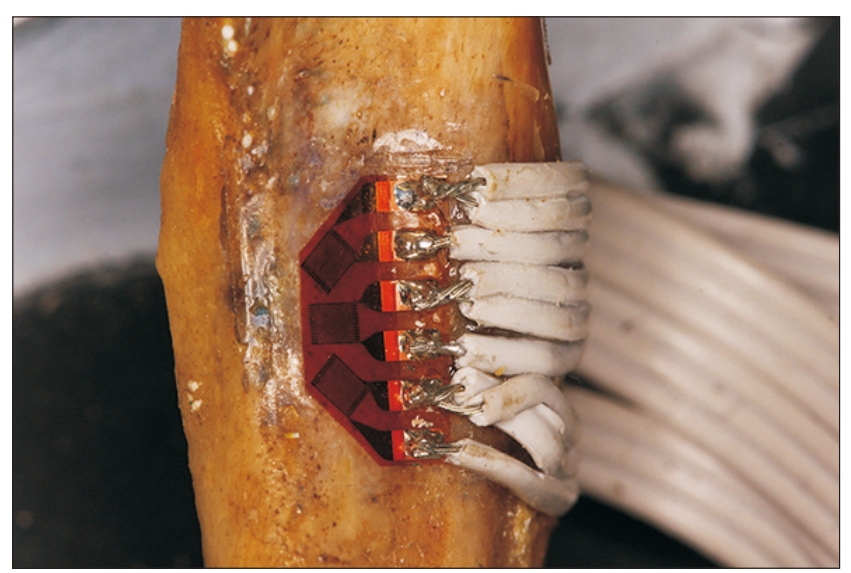

Fig. 1. Following the assembly process, all single elements of the rosettes were circuit balanced and shunt calibrated electronically in situ.

Selda Arat Bilhan et al: Evaluation of two interforaminal implants and implant-assisted removable dentures on stress distribution: an in vitro study. J Korean Assoc Oral Maxillofac Surg 2019 


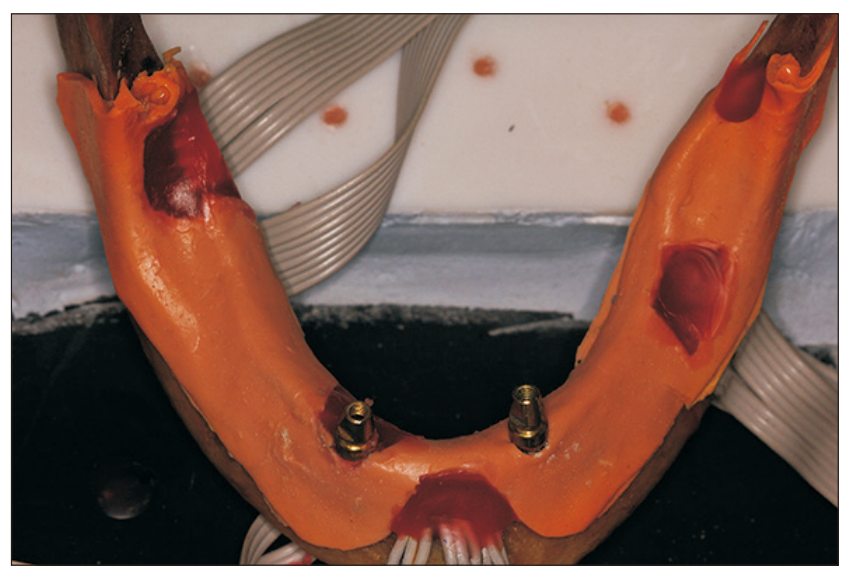

Fig. 2. A 2-mm-thick polyvinylsiloxane impression material was adapted to the mandible to mimic soft tissue.

Selda Arat Bilhan et al: Evaluation of two interforaminal implants and implant-assisted removable dentures on stress distribution: an in vitro study. J Korean Assoc Oral Maxillofac Surg 2019

with soft tissue using a reversible hydrocolloid impression material (Kromopan 100; Lascod, Florence, Italy) and was then filled with dental stone to obtain a working cast. A matching maxillary edentulous cast was selected from those used for pre-clinical education of dental students. Record bases and occlusion rims were prepared on the casts with average height and width values as described previously, and the maxillary cast with the mandible was mounted to a modified semi-adjustable articulator (Artex CT Articulator; Amann Girrbach AG, Koblach, Austria). Anatomically shaped acrylic resin artificial teeth (Trend GD Dent, Sakarya, Turkey) were arranged, and a pair of maxillary and mandibular complete dentures (MCDs) was processed and finished using heatpolymerized polymethylmethacrylate (Meliodent; Bayer UK Ltd., Newbury, UK). One MCD was duplicated from the original with a previously described method ${ }^{23}$ to create two identical dentures - one to use for the bar attachment situation and one with ball attachments. For fabrication of a surgical template, the mandibular denture was additionally duplicated using a clear heat-cured acrylic resin (Rodex, Rodent, Italy).

\section{Surgical procedures}

Two 3.8-mm-wide, 11-mm-long dental implants (Xive; Dentsply Sirona, York, PA, USA) were placed in the canine positions with the aid of a template prepared by an experienced oral and maxillofacial surgeon according to the guidelines determined by the manufacturer. During implant placement, special attention was given to obtain successful apico-

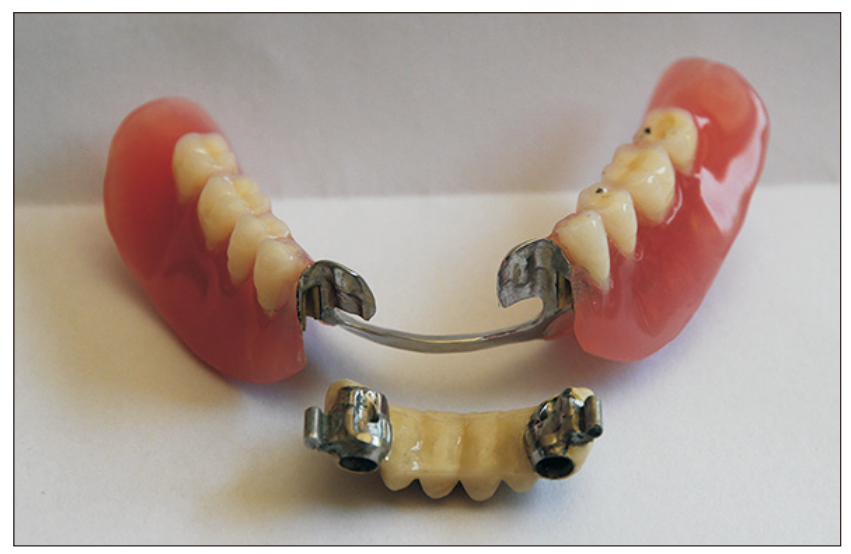

Fig. 3. The anterior bridge and the bilateral distal extension removable partial denture.

Selda Arat Bilhan et al: Evaluation of two interforaminal implants and implant-assisted removable dentures on stress distribution: an in vitro study. J Korean Assoc Oral Maxillofac Surg 2019

coronal leveling of implant shoulders.

\section{Prosthetic procedures}

An implant-level impression was created using the closed impression technique with polyvinylsiloxane impression material (Affinis light body; Coltene/Whaledent AG). Upon removal of the impression, 2 implant analogues (Xive) were placed into the replicas in the impression, and the impression was filled with type IV dental stone (GC Fujirock EP; GC Dental, Tokyo, Japan) to obtain a working cast.

Three attachment types were used to retain the mandibular prosthesis.

1) Screw-retained abutments (Xive) were screwed to the analogues; and a two-implant retained bar was fabricated, screwed to the implants, and attached to the 3 MCDs with autopolymerizing acrylic resin (Meliodent; Kulzer GmbH, Hanau, Germany) after removal of adequate acrylic using a round bur (\#140. 277. 040; Acurata Imperial, Thurmansbang, Germany).

2) Ball abutments (Xive) were screwed to the implants and attached to the remaining 3 MCDs with auto polymerizing acrylic resin (Meliodent; Kulzer $\mathrm{GmbH}$ ) after removal of adequate acrylic using a round bur (\#140. 277. 040).

3) A new set of screw-retained abutments (Xive) was added to the implants, and a 6-unit, anterior, metal fused to porcelain fixed bridge with extra coronal precision attachments and a bilateral distal extension RPD (Fig. 3) were fabricated ${ }^{38}$. Bilateral extracoronal precision attachments were used (Vario Soft 3; Bredent GmbH \& Co.KG, Senden, Germany). 


\section{Experimental procedures}

The modified semi-adjustable articulator together with the mandible that had been provided with SGs was placed under a universal testing machine (MTS Bionix-II Axial/Torsional Test System; MTS, Eden Prairie, MN, USA), and occlusal forces were applied thorough the center of the maxillary model. For strain data acquisition, a multichannel, multipurpose, universal data acquisition system (Model 8048, 128 Channel Configuration; Prosig, Fareham, UK) was used. The strains were collected in synchronization with the axial force values obtained from the MTS Controller Unit. A 40$\mathrm{kg}$ load cell (ESIT, Istanbul, Turkey) was used for optimum force measurement accuracy during the tests. Quasi static tests were subsequently conducted 10 times for each implant, and attachment configurations were performed at each of the replicated "biting" conditions: centric occlusion and left and right chewing positions. The loading and unloading rates were both $7 \mathrm{~N} / \mathrm{s}$. To exclude possible minor misalignment errors due to assembly and production tolerances, a preload of $5 \mathrm{~N}$ was placed on the system as the reference state. Each member of the strain rosette represented a one-quarter bridge. Accordingly, a total of 18 channels of data were gathered. Thermal drift was not observed during any tests.

\section{Statistical analyses}

For statistical analysis of the results, IBM SPSS Statistics (ver. 21; IBM Corp., Armonk, NY, USA) was used to analyze the measured strains from 6 SGs at 3 different loading conditions. Comparison of quantitative data was accomplished with the Mann-Whitney $U$ test for groups without normal distribution. For comparison of the 3 denture types, the Kruskal-Wallis test was used. The results were assessed at a 95\%

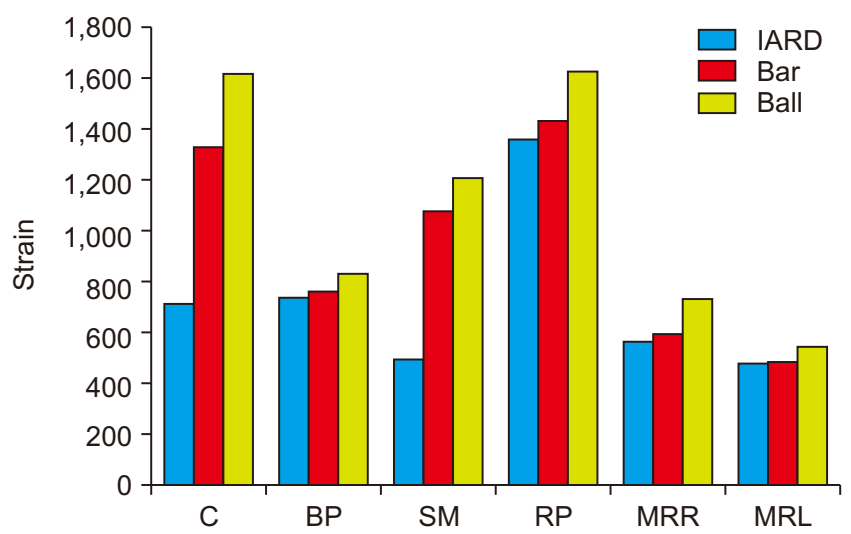

Fig. 4. Strain distribution under centric loading measured on all strain gauges. (IARD: implant-assisted removable denture, C: right canine region, BP: buccal shelf left, SM: symphysis midline, RP: right retromolar pad, MRR: right mylohyoid ridge, MRL: left mylohyoid ridge)

Selda Arat Bilhan et al: Evaluation of two interforaminal implants and implant-assisted removable dentures on stress distribution: an in vitro study. J Korean Assoc Oral Maxillofac Surg 2019

Table 1. Mean micro-strain values of different loading situations measured at all gauges

\begin{tabular}{|c|c|c|c|c|c|}
\hline & & IARD & Bar & Ball & $P$-value \\
\hline \multirow[t]{3}{*}{$\mathrm{C}$} & Centric loading & $739.70 \pm 15.78$ & $1,354.20 \pm 91.78$ & $1,641.05 \pm 20.73$ & 0.002 \\
\hline & Loading on left side & $717.60 \pm 14.44$ & $858.85 \pm 38.99$ & $987.60 \pm 20.89$ & 0.002 \\
\hline & Loading on right side & $1,692.05 \pm 45.83$ & $2,122.60 \pm 130.20$ & $2,659.50 \pm 27.24$ & 0.004 \\
\hline \multirow[t]{3}{*}{ BP } & Centric loading & $764.95 \pm 17.06$ & $785.90 \pm 15.61$ & $854.25 \pm 52.95$ & 0.002 \\
\hline & Loading on left side & $1,283.00 \pm 38.18$ & $1,414.70 \pm 50.28$ & $1,486.00 \pm 72.71$ & 0.001 \\
\hline & Loading on right side & $1,063.55 \pm 26.94$ & $1,326.65 \pm 44.09$ & $1,144.75 \pm 36.30$ & 0.045 \\
\hline \multirow[t]{3}{*}{ SM } & Centric loading & $523.80 \pm 19.44$ & $1,104.95 \pm 44.87$ & $1,235.30 \pm 38.88$ & 0.001 \\
\hline & Loading on left side & $863.95 \pm 47.14$ & $1,019.45 \pm 54.47$ & $1,142.65 \pm 15.72$ & 0.001 \\
\hline & Loading on right side & $1,240.50 \pm 49.66$ & $1,525.70 \pm 48.84$ & $1,620.30 \pm 53.58$ & 0.003 \\
\hline \multirow[t]{3}{*}{ RP } & Centric loading & $1,384.70 \pm 32.68$ & $1,450.05 \pm 22.17$ & $1,656.65 \pm 50.19$ & 0.001 \\
\hline & Loading on left side & $1,147.15 \pm 29.43$ & $1,187.15 \pm 27.46$ & $1,240.50 \pm 16.11$ & 0.007 \\
\hline & Loading on right side & $1,964.25 \pm 23.42$ & $2,071.35 \pm 38.83$ & $2,477.60 \pm 30.56$ & 0.001 \\
\hline \multirow[t]{3}{*}{ MRR } & Centric loading & $593.30 \pm 13.17$ & $617.30 \pm 40.99$ & $756.35 \pm 39.23$ & 0.002 \\
\hline & Loading on left side & $582.65 \pm 18.88$ & $586.90 \pm 35.81$ & $668.00 \pm 36.64$ & 0.013 \\
\hline & Loading on right side & $867.90 \pm 32.05$ & $906.40 \pm 48.98$ & $866.40 \pm 81.78$ & 0.289 \\
\hline \multirow[t]{3}{*}{ MRL } & Centric loading & $501.60 \pm 28.43$ & $511.60 \pm 41.38$ & $570.55 \pm 73.53$ & 0.004 \\
\hline & Loading on left side & $812.00 \pm 14.91$ & $793.90 \pm 28.44$ & $856.00 \pm 36.64$ & 0.002 \\
\hline & Loading on right side & $525.20 \pm 16.34$ & $564.10 \pm 20.20$ & $516.35 \pm 23.39$ & 0.008 \\
\hline
\end{tabular}

(IARD: implant-assisted removable denture, C: right canine region, BP: buccal shelf left, SM: symphysis midline, RP: right retromolar pad, MRR: right mylohyoid ridge, MRL: left mylohyoid ridge)

$P$-values by Kruskal-Wallis analysis.

Values are presented as mean \pm standard deviation.

Selda Arat Bilhan et al: Evaluation of two interforaminal implants and implant-assisted removable dentures on stress distribution: an in vitro study. J Korean Assoc Oral Maxillofac Surg 2019 
confidence interval for a significance level of 0.05 .

\section{Results}

Results for loading in the centric occlusion position are presented in Table 1 and Fig. 4.

The lowest strain values were measured in the IARD. The only exception was the MRL region for the ball attachment situation (136.55), whereas the highest value was observed in the $\mathrm{C}$ region for the ball attachment situation $(1,941.05)$.

Results for unilateral loading on the left side are presented in Table 1 and Fig. 5.

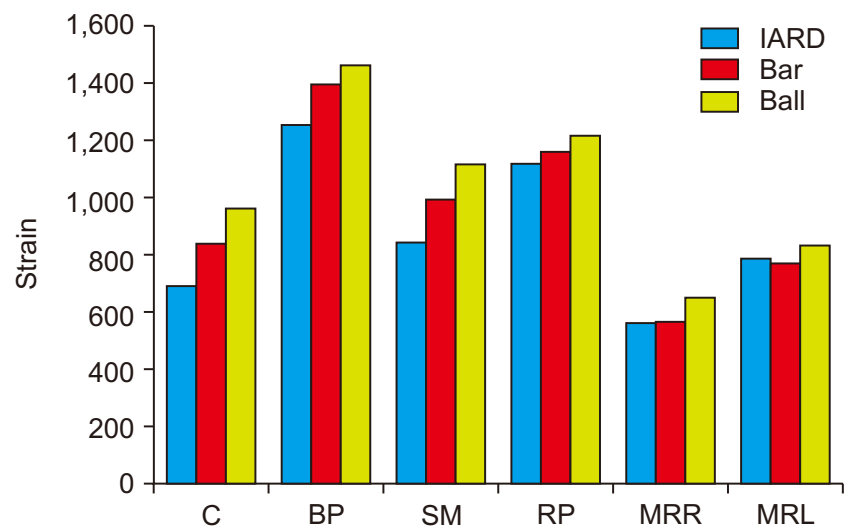

Fig. 5. Strain distribution under left side loading measured on all strain gauges. (IARD: implant-assisted removable denture, C: right canine region, BP: buccal shelf left, SM: symphysis midline, RP: right retromolar pad, MRR: right mylohyoid ridge, MRL: left mylohyoid ridge)

Selda Arat Bilhan et al: Evaluation of two interforaminal implants and implant-assisted removable dentures on stress distribution: an in vitro study. J Korean Assoc Oral Maxillofac Surg 2019
The lowest strain values were measured in the IARD, except for the MRL region for the ball attachment situation (586). The highest value was observed in the $\mathrm{C}$ region for the bar attachment situation $(1,857.6)$.

Results for unilateral loading on the right side are presented in Table 1 and Fig. 6.

The lowest strain values were measured in the IARD. The highest value was observed in the $\mathrm{C}$ region for the ball attachment situation $(1,192.05)$.

All $P$-values comparing attachment types are presented in Table 2 .

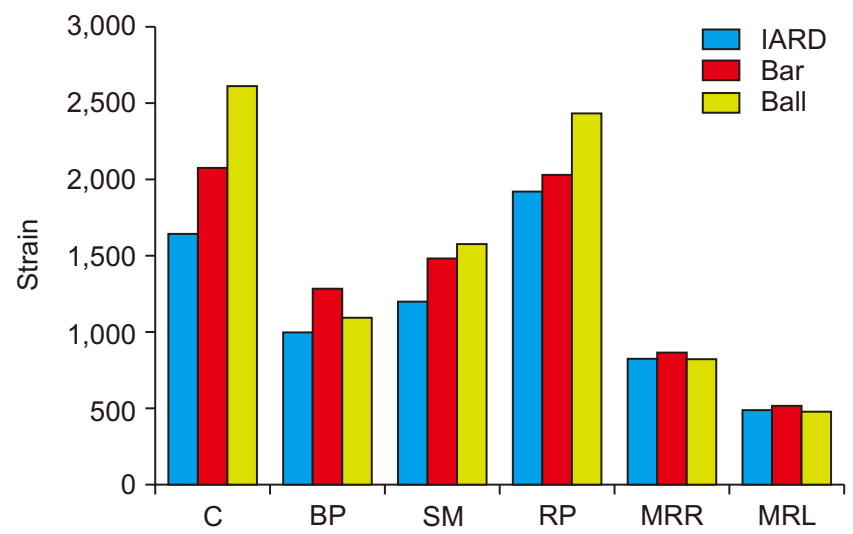

Fig. 6. Strain distribution under right side loading measured on all strain gauges. (IARD: implant-assisted removable denture, C: right canine region, BP: buccal shelf left, SM: symphysis midline, RP: right retromolar pad, MRR: right mylohyoid ridge, MRL: left mylohyoid ridge)

Selda Arat Bilhan et al: Evaluation of two interforaminal implants and implant-assisted removable dentures on stress distribution: an in vitro study. J Korean Assoc Oral Maxillofac Surg 2019

Table 2. $P$-values when comparing treatment types

\begin{tabular}{|c|c|c|c|c|c|c|}
\hline & $\mathrm{C}$ & $\mathrm{BP}$ & SM & $\mathrm{RP}$ & MRR & MRL \\
\hline \multicolumn{7}{|c|}{ Centric loading } \\
\hline Ball-bar & $0.003 *$ & 0.335 & $0.001 *$ & $0.000 *$ & 0.365 & $0.000 *$ \\
\hline Ball-IARD & $0.000 *$ & $0.000 *$ & $0.000 *$ & $0.000^{*}$ & $0.000 *$ & $0.001 *$ \\
\hline Bar-IARD & $0.001 *$ & 0.756 & $0.001 *$ & 0.554 & 0.110 & 0.365 \\
\hline \multicolumn{7}{|c|}{ Unilateral loading left side } \\
\hline Ball-bar & $0.001 *$ & 0.335 & $0.000 *$ & 1 & $0.001 *$ & $0.000 *$ \\
\hline Ball-IARD & $0.001 *$ & $0.000 *$ & $0.000 *$ & $0.001 *$ & 1.000 & 0.335 \\
\hline Bar-IARD & $0.000 *$ & $0.001 *$ & 1 & 0.050 & 0.084 & 0.084 \\
\hline \multicolumn{7}{|c|}{ Unilateral loading right side } \\
\hline Ball-bar & $0.000 *$ & $0.000 *$ & $0.000 *$ & $0.001 *$ & 0.212 & 0.212 \\
\hline Ball-IARD & $0.000 *$ & 0.015 & 0.335 & $0.000^{*}$ & 1 & 0.088 \\
\hline Bar-IARD & $0.001 *$ & $0.000 *$ & $0.001 *$ & 0.335 & 0.050 & 1 \\
\hline
\end{tabular}

(C: right canine region, BP: buccal shelf left, SM: symphysis midline, RP: right retromolar pad, MRR: right mylohyoid ridge, MRL: left mylohyoid ridge, IARD: implant-assisted removable denture)

$* P<0.01$.

$P$-values by Mann-Whitney U test.

Selda Arat Bilhan et al: Evaluation of two interforaminal implants and implant-assisted removable dentures on stress distribution: an in vitro study. J Korean Assoc Oral Maxillofac Surg 2019 


\section{Discussion}

The aim of this study was to explain the use of the presented new attachment system. If the results exhibited similar strain and/or stress distributions, the clinical treatment modalities for mandibular ISRDs could be modified to provide more economic, patient friendly, and safe solutions ${ }^{38}$. The null hypothesis of the study that IARD and ISRD would not differ on stress distribution in the edentulous mandible was rejected. The lower stress patterns observed in the IARDs show that this treatment option may be preferred for clinical use in some situations. Since information about functional loads on implants and the bone is essential to achieve longterm implant success, correct qualification and quantification of forces on implants are crucial ${ }^{10,11,39,40}$. Studies evaluating the IARD treatment option in two interforaminal implant situations are limited to a few case series ${ }^{34-37}$. The present study is the first report evaluating this type of IARDs.

Patients who can afford dental implants often have more esthetic demands and expectations of more rigid prosthetic solutions. Therefore, extracoronal precision attachments in IARDs were selected instead of conventional clasp-retained removable dentures in the present study. For biomechanical assessment of stress distribution in vitro, SG analysis is one of the most common methods used in dentistry ${ }^{38}$. The info gathered from SGs under differing experimental conditions should be regarded skeptically before clinical use because these measurements are limited to the bonded area of the gauge. The measured force levels in the present study are comparable to those measured in recent in vivo studies with SG abutments on implants ${ }^{41,42}$.

When patients use ISRDs, loads are transferred to the alveolar bone surrounding the implants as well as to residual alveolar ridges and abutments. Therefore, ISRDs depend on both implant and mucosal support ${ }^{40}$. It is important not to create negative forces on implant abutments to avoid implant damage.

The thickness of the mucosa surrounding the alveolar ridge of the mandible was $2 \mathrm{~mm}$ in the present study, in agreement with previous studies ${ }^{38,43}$. The effect of attachment type on stress distribution was studied in numerous investigations ${ }^{43-45}$, and controversies could not be eliminated. The results of a recent systematic review showed no difference in marginal bone levels around implants supporting mandibular ISRDs when different attachment systems were used ${ }^{26}$. This suggests that, even if there are differences in the forces, they are not critical to bone loss.
The results of this in vitro study indicate that, compared to retentive anchors or bar attachments, the lowest strains occurred in the new tested denture system.

Strains in the posterior mandible, such as at the retromolar pad, buccal shelf, and mylohyoid ridge, were lower with the tested attachment system for ISRDs in the present study. This result is in agreement with another investigation that reported an inverse relationship between implant strain and bearing area loading value ${ }^{11}$. Our results showed that ISRDs had the lowest denture-bearing area loading, whereas singleattachment situations exhibited relatively low implant strain and high bearing area load. The results of the present study should only be considered for forces arising during vertical occlusal loading.

The anterior fixed bridge with the precision attachment partial denture eliminates two problems of conventional attachment systems tested in the present study. First, the stability of an overdenture is hard to achieve with single attachments especially in severely resorbed alveolar ridges ${ }^{11}$, and bar types of attachments generally require more space in the denture base and are more difficult to clean ${ }^{3}$. The proposed prosthetic solution eliminates the issues of stability and increased volume of the denture as a result of the bar system, especially in the anterior region. Second, the fixed part of the denture may increase the self-confidence of the patient. As shown in a recent study, wear of the matrices of single attachments are more noticeable when implants are divergently inserted ${ }^{4}$, requiring more maintenance over a shorter period of service. It was determined that the ideal solution in cases of divergent implants are splinted attachment types ${ }^{8}$. Therefore, the IARD solution is suitable for this kind of situation.

With the use of the described technique, it was not possible to quantify bone-implant interface strains, a limitation of the present study. Therefore, the results of the present study should be considered with caution. Although the in vivo situation was mimicked as ideally as possible, the results obtained from the in vitro experiments should be tested and confirmed in clinical follow-up studies before strict conclusions are drawn. However, the results encourage clinical use of the suggested fixed anterior bridge with precision attachments and RPD, since its esthetic and functional advantages are accompanied by favorable force distribution in the mandible. Use of IARDs is a good alternative to other attachment designs when 2 implants are inserted in the anterior region of the mandible. 


\section{Conclusion}

Within the limitations of the present study, it can be concluded that an IARD may be a reasonable and valuable alternative to ball attachments or a bar in two interforaminal implants situations, especially when the patients prefer to have their teeth as fixed prosthesis even when they remove thir dentures. The in vitro results are qualitative in nature, and their clinical significance should be tested and confirmed in clinical studies.

\section{ORCID}

Selda Arat Bilhan, https://orcid.org/0000-0003-2647-6245

Onur Geckili, https://orcid.org/0000-0002-7852-3915

Altug Cilingir, https://orcid.org/0000-0002-0694-5772

Ergun Bozdag, https://orcid.org/0000-0002-8942-6627

Hakan Bilhan, https://orcid.org/0000-0003-1787-3003

\section{Authors' Contributions}

S.A.B. contributed experimental procedures, and data collection. O.G. contributed drafting article, critical revision of article, and approval of article. A.C. contributed data analysis and interpretation. E.B. contributed experimental procedures. H.B. contributed critical revision of article.

\section{Conflict of Interest}

No potential conflict of interest relevant to this article was reported.

\section{References}

1. Zarb GA, Schmitt A. The longitudinal clinical effectiveness of osseointegrated dental implants: the Toronto Study. Part II: the prosthetic results. J Prosthet Dent 1990;64:53-61.

2. Burns DR, Unger JW, Elswick RK Jr, Beck DA. Prospective clinical evaluation of mandibular implant overdentures: part I--retention, stability, and tissue response. J Prosthet Dent 1995;73:354-63.

3. Burns DR, Unger JW, Coffey JP, Waldrop TC, Elswick RK Jr. Randomized, prospective, clinical evaluation of prosthodontic modalities for mandibular implant overdenture treatment. J Prosthet Dent 2011;106:12-22.

4. Ortegón SM, Thompson GA, Agar JR, Taylor TD, Perdikis D. Retention forces of spherical attachments as a function of implant and matrix angulation in mandibular overdentures: an in vitro study. $\mathrm{J}$ Prosthet Dent 2009;101:231-8.

5. Geckili O, Bilhan H, Mumcu E, Dayan C, Yabul A, Tuncer N. Comparison of patient satisfaction, quality of life, and bite force between elderly edentulous patients wearing mandibular two implant-supported overdentures and conventional complete dentures after 4 years. Spec Care Dentist 2012;32:136-41.

6. Geckili O, Bilhan H, Bilgin T. Impact of mandibular two-implant retained overdentures on life quality in a group of elderly Turkish edentulous patients. Arch Gerontol Geriatr 2011;53:233-6.

7. Naert I, Alsaadi G, Quirynen M. Prosthetic aspects and patient satisfaction with two-implant-retained mandibular overdentures: a 10year randomized clinical study. Int J Prosthodont 2004;17:401-10.

8. Walton JN, Huizinga SC, Peck CC. Implant angulation: a measurement technique, implant overdenture maintenance, and the influence of surgical experience. Int J Prosthodont 2001;14:523-30.

9. Geckili O, Bilhan H, Bilgin T. Locator attachments as an alternative to ball attachments in 2-implant retained mandibular overdentures. J Can Dent Assoc 2007;73:691-4.

10. Trakas T, Michalakis K, Kang K, Hirayama H. Attachment systems for implant retained overdentures: a literature review. Implant Dent 2006; 15:24-34.

11. Heckmann SM, Winter W, Meyer M, Weber HP, Wichmann MG. Overdenture attachment selection and the loading of implant and denture-bearing area. Part 2: a methodical study using five types of attachment. Clin Oral Implants Res 2001;12:640-7.

12. Osman RB, Payne AG, Ma S. Prosthodontic maintenance of maxillary implant overdentures: a systematic literature review. Int J Prosthodont 2012;25:381-91.

13. Bakke M, Holm B, Gotfredsen K. Masticatory function and patient satisfaction with implant-supported mandibular overdentures: a prospective 5-year study. Int J Prosthodont 2002;15:575-81.

14. Bergendal T, Engquist B. Implant-supported overdentures: a longitudinal prospective study. Int J Oral Maxillofac Implants 1998;13:253-62.

15. Karabuda C, Tosun T, Ermis E, Ozdemir T. Comparison of 2 retentive systems for implant-supported overdentures: soft tissue management and evaluation of patient satisfaction. J Periodontol 2002;73:1067-70.

16. MacEntee MI, Walton JN, Glick N. A clinical trial of patient satisfaction and prosthodontic needs with ball and bar attachments for implant-retained complete overdentures: three-year results. J Prosthet Dent 2005;93:28-37.

17. Mumcu E, Bilhan H, Geckili O. The effect of attachment type and implant number on satisfaction and quality of life of mandibular implant-retained overdenture wearers. Gerodontology 2012;29:e618-23.

18. Kleis WK, Kämmerer PW, Hartmann S, Al-Nawas B, Wagner W. A comparison of three different attachment systems for mandibular two-implant overdentures: one-year report. Clin Implant Dent Relat Res 2010;12:209-18.

19. Cune M, van Kampen F, van der Bilt A, Bosman F. Patient satisfaction and preference with magnet, bar-clip, and ball-socket retained mandibular implant overdentures: a cross-over clinical trial. Int J Prosthodont 2005;18:99-105.

20. Davis DM, Packer ME. Mandibular overdentures stabilized by Astra Tech implants with either ball attachments or magnets: 5-year results. Int J Prosthodont 1999;12:222-9.

21. Chaytor DV, Zarb GA, Schmitt A, Lewis DW. The longitudinal effectiveness of osseointegrated dental implants. The Toronto Study: bone level changes. Int J Periodontics Restorative Dent 1991;11:112-25.

22. Donatsky O. Osseointegrated dental implants with ball attachments supporting overdentures in patients with mandibular alveolar ridge atrophy. Int J Oral Maxillofac Implants 1993;8:162-6.

23. Boerrigter EM, van Oort RP, Raghoebar GM, Stegenga B, Schoen PJ, Boering G. A controlled clinical trial of implant-retained mandibular overdentures: clinical aspects. J Oral Rehabil 1997;24:18290.

24. Burns DR. Mandibular implant overdenture treatment: consensus and controversy. J Prosthodont 2000;9:37-46.

25. Naert I, Alsaadi G, van Steenberghe D, Quirynen M. A 10-year randomized clinical trial on the influence of splinted and unsplinted 
oral implants retaining mandibular overdentures: peri-implant outcome. Int J Oral Maxillofac Implants 2004;19:695-702.

26. Cehreli MC, Karasoy D, Kökat AM, Akça K, Eckert S. A systematic review of marginal bone loss around implants retaining or supporting overdentures. Int J Oral Maxillofac Implants 2010;25:26677.

27. Roos-Jansåker AM, Franke-Stenport V, Renvert S, Albrektsson T, Claffey N. Dog model for study of supracrestal bone apposition around partially inserted implants. Clin Oral Implants Res 2002;13:455-9.

28. Brunski J, Block MS, Guerra LR. Biomechanics of dental implants. In: Block MS, Kent JN, Guerra L, eds. Implants in dentistry: essentials of endosseous implants for maxillofacial reconstruction. Philadelphia: W.B. Saunders; 1997:63-71.

29. Bilhan H, Mumcu E, Arat S. The comparison of marginal bone loss around mandibular overdenture-supporting implants with two different attachment types in a loading period of 36 months. Gerodontology 2011;28:49-57.

30. Bergkvist G, Simonsson K, Rydberg K, Johansson F, Dérand T. A finite element analysis of stress distribution in bone tissue surrounding uncoupled or splinted dental implants. Clin Implant Dent Relat Res 2008;10:40-6.

31. Bassetti RG, Bassetti MA, Kuttenberger J. Implant-assisted removable partial denture prostheses: a critical review of selected literature. Int J Prosthodont 2018;31:287-302.

32. Wismeijer D, Tawse-Smith A, Payne AG. Multicentre prospective evaluation of implant-assisted mandibular bilateral distal extension removable partial dentures: patient satisfaction. Clin Oral Implants Res 2013;24:20-7.

33. Payne AG, Tawse-Smith A, Wismeijer D, De Silva RK, Ma S. Multicentre prospective evaluation of implant-assisted mandibular removable partial dentures: surgical and prosthodontic outcomes. Clin Oral Implants Res 2017;28:116-25.

34. Starr NL. The distal extension case: an alternative restorative design for implant prosthetics. Int J Periodontics Restorative Dent 2001;21:61-7.

35. Feinberg E. Precision attachment case restoration with implant abutments: a review with case reports. J Oral Implantol 2011;37:489-98.

36. Pellecchia M, Pellecchia R, Emtiaz S. Distal extension man- dibular removable partial denture connected to an anterior fixed implant-supported prosthesis: a clinical report. J Prosthet Dent 2000;83:607-12.

37. Chronopoulos V, Sarafianou A, Kourtis S. The use of dental implants in combination with removable partial dentures: a case report. J Esthet Restor Dent 2008;20:355-64; discussion 365.

38. Bilhan $\mathrm{H}$. The role of the dental implant in removable partial dentures. In: Şakar O, ed. Removable partial dentures: a practitioners' manual. Cham: Springer International Publishing; 2016:195-208.

39. English CE. Bar patterns in implant prosthodontics. Implant Dent 1994;3:217-29.

40. Machado AC, Cardoso L, Brandt WC, Henriques GE, de Arruda Nóbilo MA. Photoelastic analysis of the distribution of stress in different systems of overdentures on osseous-integrated implants. J Craniofac Surg 2011;22:2332-6.

41. Nishioka RS, de Vasconcellos LG, de Melo Nishioka LN. External hexagon and internal hexagon in straight and offset implant placement: strain gauge analysis. Implant Dent 2009;18:512-20.

42. Rangert B, Gunne J, Glantz PO, Svensson A. Vertical load distribution on a three-unit prosthesis supported by a natural tooth and a single Brånemark implant. An in vivo study. Clin Oral Implants Res 1995;6:40-6.

43. Haruta A, Matsushita Y, Tsukiyama Y, Sawae Y, Sakai N, Koyano K. Effects of mucosal thickness on the stress distribution and denture stability of mandibular implant-supported overdentures with unsplinted attachments in vitro. J Dent Biomech 2011;2011:894395.

44. Menicucci G, Lorenzetti M, Pera P, Preti G. Mandibular implantretained overdenture: finite element analysis of two anchorage systems. Int J Oral Maxillofac Implants 1998;13:369-76.

45. Thayer HH, Caputo AA. Photoelastic stess analysis of overdenture attachments. J Prosthet Dent 1980;43:611-7.

How to cite this article: Arat Bilhan S, Geckili O, Cilingir A,

Bozdag E, Bilhan H. Evaluation of two interforaminal implants

and implant-assisted removable dentures on stress distribution: an

in vitro study. J Korean Assoc Oral Maxillofac Surg 2019;45:199-

206. https://doi.org/10.5125/jkaoms.2019.45.4.199 